\title{
Người Việt góp sức "gác cửa" các ấn phẩm khoa học quốc tế: Góc nhìn từ Publons Peer Review Awards 2018
}

Theo Hồ Mạnh Toàn (sc.sshpa.com) 13/09/2018 10:10

Ở hạng mục những nhà bình duyệt thuộc top $1 \%$ của 23 ngành khoa học của Giải thưởng Bình duyệt Publons 2018, có tổng cộng 25 nhà nghiên cứu Việt Nam.

Sau nhiều ngày chờ đợi, cuối cùng Publons (thuộc Clarivate Analytics Web of Science) đã gọi tên những nhà bình duyệt, biên tập viên, viện nghiên cứu có những thành tựu và đóng góp không mệt mỏi cho bình duyệt khoa học trong năm 2018. Để có dữ liệu này, Publons đã kết nối với các cơ sở dữ liệu của Clarivate Web of Science, và ScholarOne. Dữ liệu đóng vào ngày 1-9-2018, và phủ kín giai đoạn từ 1-9-2017 đến 1-9-2018.

Tại Publons' 2018 Peer Review Awards, diễn ra từ 10 tới 15-9-2018, có hơn 6000 chuyên gia đến từ 100 quốc gia và 2000 cơ quan khác nhau đã được vinh danh vì những đóng góp thầm lặng, miệt mài cho khoa học, ở ngay tại trái tim của hệ thống xuất bản hiện đại: bình duyệt bản thảo (còn gọi là bình xét, phản biện).

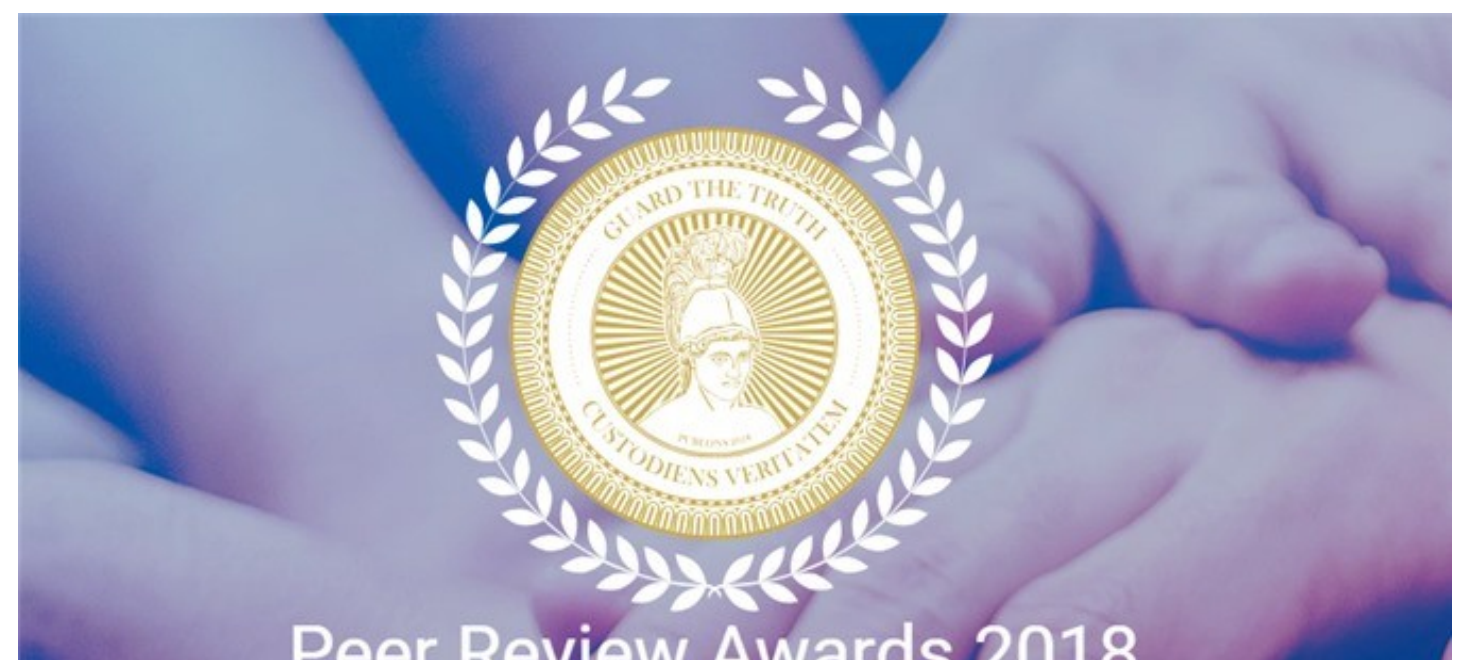




\section{Celebrating the value of review and the critical role of} reviewers

Trong hạng mục top 10 nhà bình duyệt xuất sắc, tác giả người Bồ Đào Nha Maria Alzira Pimenta Dinis (University Fernando Pessoa, Bồ Đào Nha) đứng đâuu với 84 bài bình duyệt được đánh giá xuất sắc.

Biên tập viên Christopher Blanford của tạp chí Journal of Material Science (Journal Impact Factor 2017: 2.993; Springer) dẫn đầu hạng mục các biên tập viên điều phối xuất sắc nhất với 2886 bản thảo, gấp đôi con số 1341 của người thứ hai là biên tập viên John Hancock của tạp chí Bioinfomatics (có Journal Impact Factor 2017 : 5.481; Oxford University Press).

Tại hạng mục các nhà bình duyệt chất lượng nhất của các tạp chí hàng đầu, 10 nhà bình duyệt của tạp chí của MDPI là Sustainability (JIF 2017 : 2.075) đã hoàn thành 9314 bài bình duyệt để đưa tạp chí này dẫn đầu trong top 30 tạp chí. Tiếp theo là Energies (JIF 2017: 2.676) với 7901 bài bình duyệt. Các tạp chí có tiếng như PLOS ONE (JIF 2017: 2.766) hay Scientific Reports (của Nature với JIF 2017 là 4.122: https://www.nature.com/srep/) xếp thứ 5 và 10 .

Tại hạng mục dành cho các nhà nghiên cứu trẻ, nhà nghiên cứu Xinyan Huang (Hong Kong Polytechnic University, Hong Kong) đã trở thành gương mặt được bình chọn vì những đóng góp xuất sắc của anh cho bình duyệt dù tuổi nghề còn rất trẻ.

Cuối cùng, hạng mục giải thưởng được trông đợi nhất chính là những nhà bình duyệt thuộc top $1 \%$ của 22 ngành trong hệ thống Essential Science Indicators (ESI) và ngành thứ 23 - Assorted - là tổng hợp tất cả các ngành khác nằm ngoài nhóm 22 ngành của ESI. Theo thống kê của SSHPA, có tổng cộng 25 nhà nghiên cứu Việt Nam thuộc top $1 \%$ của 23 ngành, tuy nhiên chỉ có 5 người là đang làm việc trong nước. Ngành Kĩ thuật và Khoa học máy tính là 2 ngành có nhiều nhà bình duyệt người Việt nhất.

Một số gương mặt tiêu biểu có thể kể đến nhà nghiên cứu trẻ Dương Minh Quân (Politecnico Di Milano và Đại học Đà Nẵng) đã 2 năm liên tiếp đạt giải Top Reviewers không chỉ trong ngành mà còn là trong trường Politecnico Di Milano, và cũng là tác giả có liên tiếp các bài trên tạp chí Energies (JIF 2017: 2.676) đã nêu ở trên. Nhà nghiên cứu từng thuộc top $1 \%$ những nhà khoa học ảnh hưởng nhất thế giới năm 2015 - nhà nghiên cứu lừng lẫy Nguyễn Xuân Hùng (Đại Học Bách Khoa Thành Phố Hồ Chí Minh) cũng đã hai năm liên tiếp thuộc Top Reviewers: 2017 là ngành Kĩ thuật và 2018 là ngành Khoa học vật liệu. 
Nhà bình duyệt người Việt có thứ hạng cao nhất là tác giả Nguyễn Văn Định, \#13 ngành Khoa học máy tính, cũng là một nhà khoa học trẻ hiện đang nghiên cứu tại Soongsil University, Hàn Quốc.

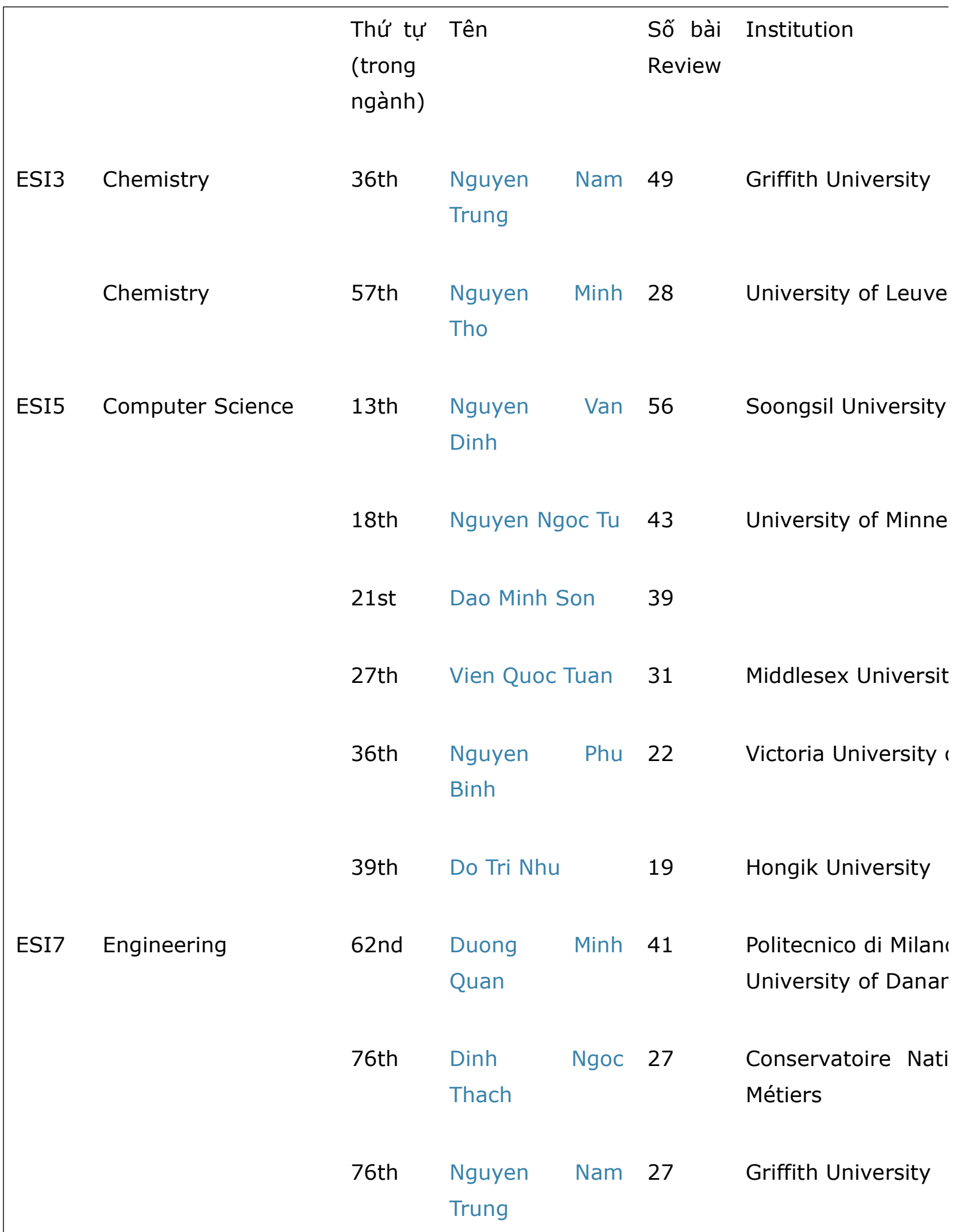




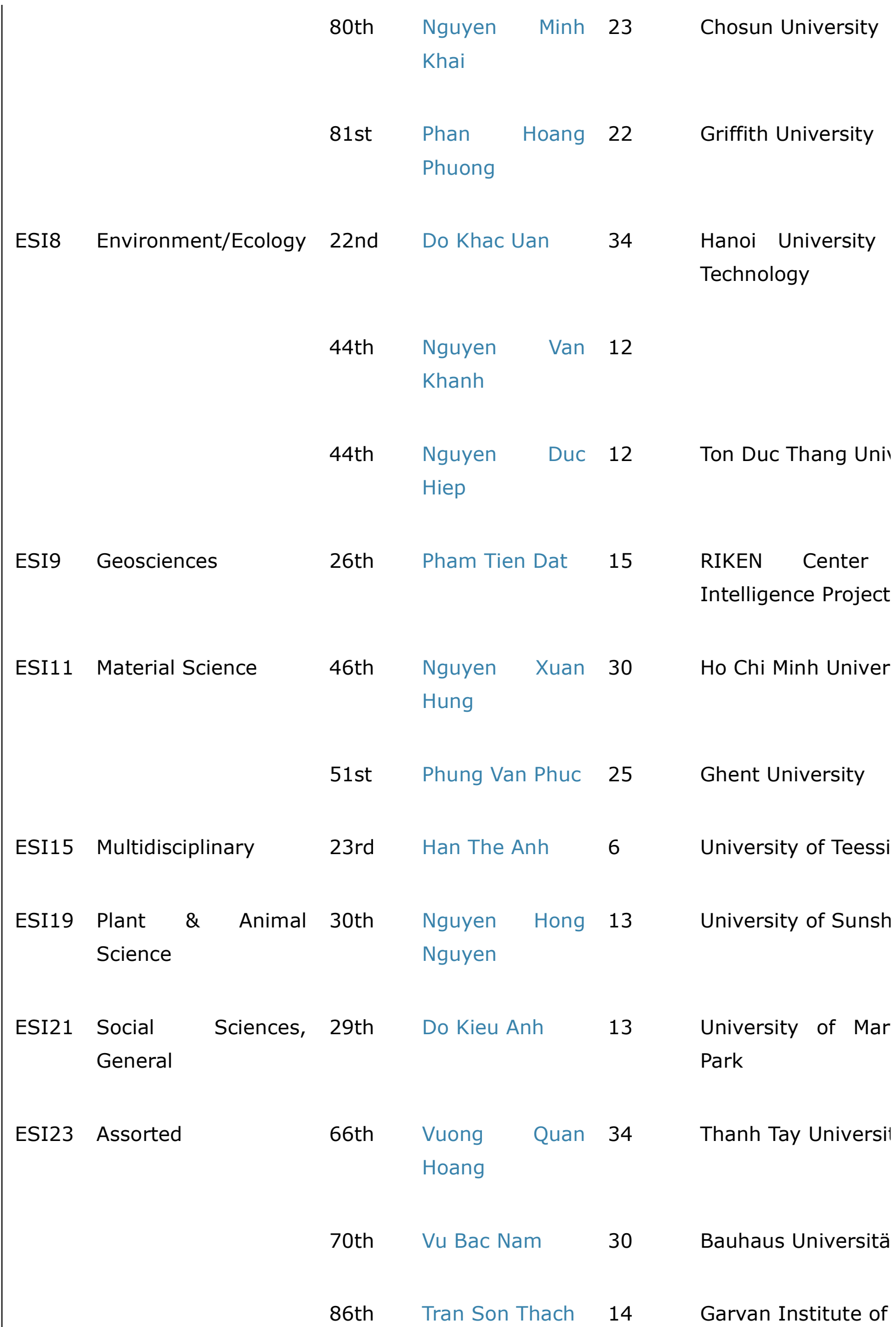


Giải thưởng Publons' 2018 Peer Review Awards không chỉ ghi nhận đóng góp của những nhà bình duyệt có thâm niên mà còn là nơi những nhà nghiên cứu trẻ có thể khẳng định bản thân mình. Hơn 6000 nhà khoa học được thống kê chắc chắn sẽ là động lực để có thêm nhiều nhà khoa học cố gắng hơn nữa và tiếp tục đóng góp cho khoa học.

\section{Nguồn:}

https://sc.sshpa.com/post/4291

Theo Hồ Mạnh Toàn (sc.sshpa.com) 